\title{
UNDERSTANDING TEMPERATURE EFFECTS ON FRICTION AT TOOL - CFRP WORKPIECE INTERFACE USING OPEN-LOOP FRICTION TESTING
}

\author{
S. Ashworth ${ }^{1 *}$, K. Kerrigan ${ }^{1}$ \\ ${ }^{1}$ Advanced Manufacturing Research Centre with Boeing, The University of Sheffield, Rotherham, S60 5TZ, UK \\ ${ }^{*}$ Corresponding author; e-mail: sam.ashworth@sheffield.ac.uk
}

\begin{abstract}
Cutting processes of carbon fibre reinforced polymer (CFRP) material generate significant energy in the form of heat which can be detrimental to final surface and sub-surface quality. By artificially changing the temperature of the workpiece to simulate cutting temperatures, thermal effects on friction metrics can be understood. Feed rate and CFRP pre-heating for macro and nanoscale open loop pin on plate friction testing has been completed for two aerospace grade CFRP materials with steel, carbide and coated carbide pins to give an insight to fundamental tool wear that occurs in CFRP machining.
\end{abstract}

\section{Keywords:}

CFRP; machining; friction; HSS; carbide; CVD coated carbide

\section{INTRODUCTION}

CFRP materials see ever increasing use in the aerospace industry [ATI 2018] due to a high specific strength to weight ratio [Ashby 2011]. Machining operations such as milling or drilling are required to achieve final part shape and assembly requirements [Sheikh-Ahmad 2008]. Machining of CFRP is considered difficult when compared to metallic machining due to the anisotropic and abrasive nature of the fibre material [Wang et al. 1995]. This abrasive nature can wear tools and render the cutting edge less effective which can lead to surface quality defects including delamination. The tool is therefore changed frequently to improve surface quality which increases overall machining costs [Faraz et al. 2009]. To counter tool wear, hard wearing materials such as polycrystalline diamond (PCD) and chemical vapour deposition (CVD) diamond like coatings are employed. This also minimises various damage modes such as delamination, uncut fibres and matrix smearing on the cut surface [Teti 2002]. Another challenge in the machining of CFRP is the generation of significant heat which can also damage the material leaving matrix smearing or reducing the support of the fibres during cutting which in turn increases cutting forces [Ashworth et al. 2019] and potentially increases tool wear.

The links between heat, tool wear and fundamental friction in CFRP machining processes have been qualitatively quantified [Kerrigan and Scaife 2018] and to some extent quantitatively using closed loop systems [Xu et al. 2018].

In addition to providing an insight to the effects of heat generation and tool wear, contact friction between tool and workpiece is a parameter used extensively in analytica models of cutting. Accurate values are required to correctly simulate cutting techniques through finite element analysis
(FEA) [Chardon et al. 2015, Voss et al. 2019, CeperoMejías et al. 2020].

Fig. 1 shows the multitude of in-process and final part parameters that are influenced by the friction descriptor. As all of these effects are related to friction, it is imperative that this can be measured effectively. This is achieved through tribology testing. As friction relates all of these parameters, there is also potential for it to be used as a machinability measure, removing the need to measure each metric individually.

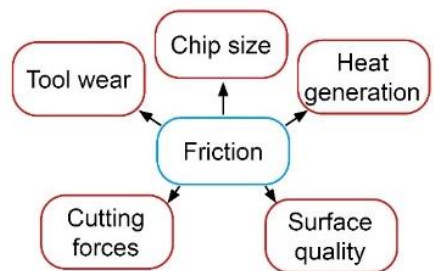

Fig. 1: Parameters influenced by friction in CFRP machining

Tribology tests are able to measure apparent friction, $\mu_{\text {app }}$, which can be described as the ratio between tangential $\left(F_{T}\right)$ and normal forces $\left(F_{N}\right)$ given by Eq. 1 .

$\mu_{\text {app }}=\frac{F_{T}}{F_{N}}$

Traditionally closed loop tribology systems have been used to characterise friction where two contacting bodies, in relative motion with each other, do not come into contact with fresh material. Authors [Lorain et al. 2019, Sterle et al. 2019] have shown significant differences in friction values between open and closed test methods. The open system is seen as advantageous by many authors [Mondelin et al. 
2010, Puls et al. 2012, Voss et al. 2017]. This is due to the method being more comparable to actual machining processes, where new material is cut is seen at the cutting interface as the cutting tool progresses through the workpiece. Conversely, the closed loop process allows damaged fibres and resins into the contact zone which is not reflective of the cutting process. This is an issue for CFRP friction observations as new material is anisotropic and fibre orientations are defined during manufacturing of laminates. Closed loop systems allow pin contact with fibres and resins that have been damaged, allowing nonrepresentative contact in terms of fibre orientations and resin fractions.

Of the limited previous open loop work [Mondelin et al. 2010, Voss et al. 2017], only a limited number of papers have explored the relationship between heat and friction. The effect of changing velocities on friction and heat flux has been explored [Chardon et al. 2015], but temperature has not been observed directly. Additionally this experiment used chopped strand material which may provide different friction properties than continuous fibres used in aerospace grade parts. Testing at elevated temperatures offers potential to explore friction at temperatures typical of the cutting process which can exceed the materials glass transition $\left(T_{g}\right)$ temperature $\left(\sim 200^{\circ} \mathrm{C}\right.$ for epoxy based materials) [Ashworth et al. 2019]. The onset of $T_{g}$ is where the material changes from a glassy to a rubbery state which may adversely affect friction. Understanding friction at realistic cutting temperatures is critical, especially in FEA simulations.

\section{AIMS}

The overall aim of this body of work is to investigate how friction is changed by various parameters which relate to the CFRP machining process, as shown in Fig. 2.

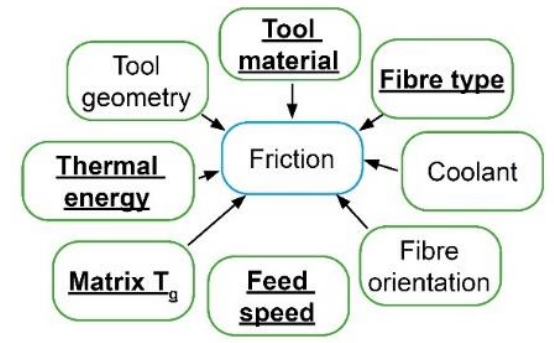

Fig. 2: Parameters that potentially alter friction in CFRP machining (bold and underlined shows the parameters investigated in this study)

By understanding these effects, productivity improvement through cutting strategy optimisation can be completed. It is also anticipated that these trials will pave the way for friction coefficients that are tailored to individual CFRP fibre and matrix materials as well as cutting tool material to allow increased FEA accuracy.

Specifically, this experiment aims to complete open loop tribology testing for different feed rates and at different CFRP pre-heat temperatures which are more comparable to machining temperatures than previously explored in literature. Different feed rates are investigated to determine how different levels of productivity alter the friction which will give fundamental insights into tool wear. Separating temperature from the machining process in order to optimise parameters and achieve cost savings is difficult to complete. By artificially changing the temperature of the workpiece to simulate cutting temperatures, the friction effects can be understood and may lead to a parameter that can be tuned to create savings.

\section{EXPERIMENTAL SETUP}

\subsection{Experimental design}

The experiment is split into three sections which encompass initial pin on plate tests for feed rate changes, pin on plate tests for pre-heated CFRP and nanoscale friction testing of pre-heated CFRP.

\section{Feed rate trials}

Fig. 3 shows the experimental setup to allow a $600 \mathrm{~mm}$ traverse distance for the pin on plate testing with forces recorded via a rotating dynamometer (RCD).

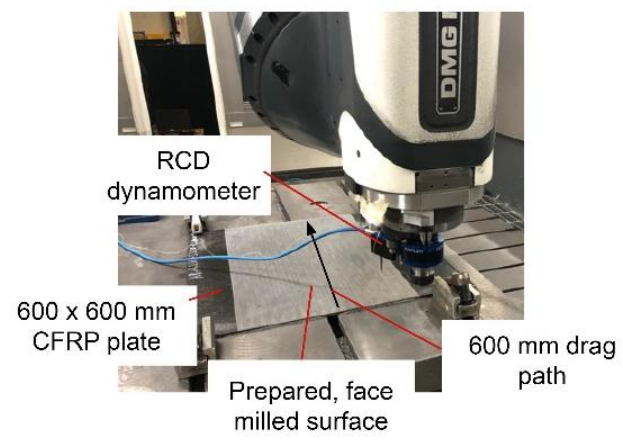

Fig. 3: Experimental setup for feed rate trial

The experiment used 3 levels of feed rate; 1, 10 and 50 $\mathrm{m} / \mathrm{min}, 3$ pin materials; high speed steel (HSS), carbide (OSG Corp.) and CVD (OSG Corp.) with $6 \mathrm{~mm}$ radius and $20 \mathrm{~mm}$ length and two CFRP materials; 5320-1 and M21. Each combination was repeated three times using new pins for each trial to minimise the effect of wear and using fresh material in a $600 \mathrm{~mm}$ drag path.

\section{CFRP pre-heat macro trials}

Fig. 4 shows the experimental setup for macro CFRP preheat trials which allowed for a $300 \mathrm{~mm}$ traverse distance for the pin on plate testing. A $300 \times 300 \mathrm{~mm}$ aluminium panel was used with $4 \times 10 \mathrm{~mm}$ diameter, $500 \mathrm{~W}$ cartridge heaters to heat the CFRP plate with PID control. $3 x$ thermocouple's (TC's) were embedded into the CFRP plate to ensure steady state temperature across the panel prior to pin on plate tests. A single TC was also embedded in the pin to record pin temperature during the trial.

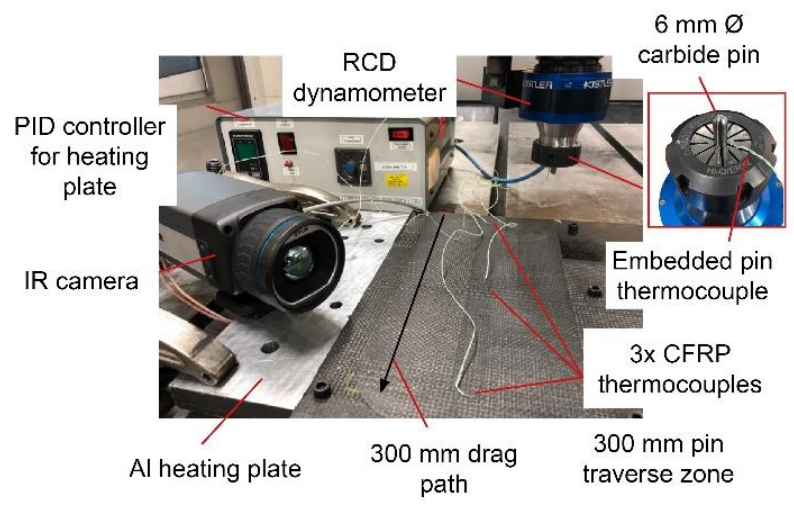

Fig. 4: Experimental setup for CFRP pre-heat macro trials

The experiment used 4 levels of CFRP pre-heating; room temperature (RT) $\left(23^{\circ} \mathrm{C}\right), 75,100$ and $130{ }^{\circ} \mathrm{C}$, and two CFRP materials; 5320-1 and M21. Each combination was repeated three times. 


\section{Nanoscale pre-heat trials}

Nanoscale testing at differing elevated temperatures (RT $\left(23^{\circ} \mathrm{C}\right), 100,150$ and $\left.175^{\circ} \mathrm{C}\right)$ was completed to assess $\mu_{\text {app }}$ at the resin region only for both 5320-1 and M21 CFRP materials. This supplements the macro scale, bulk fibre/resin testing of the aforementioned experimenta designs and serves to determine differences between the macro and the micro-scale. Each test was replicated five times.

\subsection{CFRP material}

This experiment uses two $600 \times 600 \times \sim 5 \mathrm{~mm}$ CFRP panels made from;

- 28 plies of Solvay Cycom 5320-1, a $2 \times 2$ twill material, laid in a quasi isotropic $\left[(0 / 90)_{F},( \pm 45)_{F}\right] 7 \mathrm{~S}$ manner.

- 16 plies of Hexcel M21, a $2 \times 2$ twill material laid in quasi isotropic $\left[(0 / 90)_{\mathrm{F}},( \pm 45)_{\mathrm{F}}\right]_{4 \mathrm{~S}}$ manner.

Both material types are toughened epoxy resin systems however the 5320-1 has a smaller fibre tow count of $3 \mathrm{k}$ compared to the M216k.

Dynamic mechanical analysis (DMA) using a TA DMA Q800 machine in a three point bend clamping configuration was completed. Testing used a ramp rate of $5^{\circ} \mathrm{C} / \mathrm{min}$ from 30 to $250{ }^{\circ} \mathrm{C}$ and a frequency of $1 \mathrm{~Hz}$. This provided a tan delta $T_{g}$ of 209.3 and $202.7^{\circ} \mathrm{C}$ for $5320-1$ and M21 material, respectively.

Prior to the trials, a face milling tool to remove the resin rich top layer of the CFRP panels to expose $\pm 45^{\circ}$ fibre plies in both material cases.

\subsection{Pin material, geometry and surface roughness}

The radius of pins was measured through an Alicona G4 to monitor wear. The focus variation microscopy was completed at $5 \mathrm{x}$ zoom, $0.5 \mu \mathrm{m}$ and $4 \mu \mathrm{m}$ vertical and horizontal resolution to capture the pin nose geometry. 9 pins per material were utilised throughout the experiment with rotations prior to each test to ensure the fresh, unworn pin material contacted the CFRP material for each pin on plate test. Examination of the pin material after testing showed negligible pin wear $(<0.1 \%$ change in radius) as a consequence of the experimental design.

$1 \mathrm{~mm}$ diameter bores were placed into the pins using an electrical discharge machining process to a depth of $18 \mathrm{~mm}$ to allow thermocouple placement $2 \mathrm{~mm}$ from the contact zone, as shown in Fig. 5.

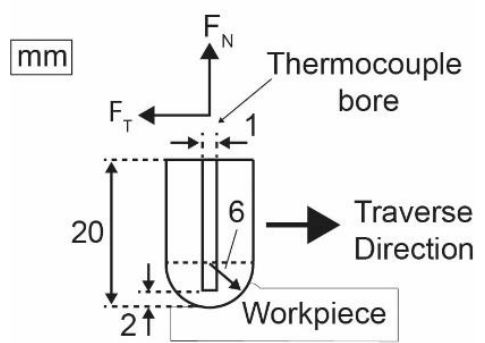

Fig. 5: Pin geometry and dimensions

Surface quality of the pins was observed through focus variation methods at the same radius observation resolution of $0.5 \mu \mathrm{m}$ and $4 \mu \mathrm{m}$ vertical and horizontal resolution but at $20 \mathrm{x}$ zoom. $\lambda_{c}$, the cut-off wavelength to isolate roughness from form, was set to $80 \mu \mathrm{m}$ to allow for the form of the material to be sufficiently removed to measure the average mean height of the surface $\left(S_{a}\right)$ on the material surface and an area of at least $0.15 \mathrm{~mm}^{2}$ observed.

\subsection{Machine tool}

A DMU340G 5-axis machining centre was chosen due to the linear feed drives that provided high feed rates (up to 50 $\mathrm{m} / \mathrm{min})$, low acceleration time $\left(3 \mathrm{~ms}^{-1}\right)$ and an ability to lock the spindle to prevent pin rotation during movements. The machine tool positional accuracy is given as $\pm 0.15 \mu \mathrm{m}$ making it an ideal choice to maintain a constant depth which was set to $-0.3 \mathrm{~mm}$ from the face milled CFRP surface and confirmed through slip gauges prior to each pin on plate test. In addition to spindle locking, the $\mathrm{C}$-axis of the machine was also locked. Pins were held by an ER32 collet tightened to $40 \mathrm{Nm}$.

\subsection{Data acquisition equipment}

$0.8 \mathrm{~mm}$ k-type, PFA insulated, thermocouple (TC) wires were embedded into pins with an acrylic resin with a thermal conductivity of $0.82 \mathrm{~W} / \mathrm{m} . \mathrm{K}$. The same TC's were mounted in $0.5 \mathrm{~mm}$ diameter holes drilled to a depth of 2.5 $\mathrm{mm}$ at 3 positions during CFRP pre-heat trials to monitor the CFRP temperature. The TC's were connected to a NI PXle-4353 thermocouple data acquisition (DAQ) module mounted in a NI PXle-1078 chassis with automatic cold junction compensation. NI Flexlogger was used to record at a rate of $90 \mathrm{~Hz}$ for the duration of trials.

To confirm TC temperature monitoring, a FLIR A655sc infra-red (IR) camera was used to observe the temperature of the pin after the pass at $30 \mathrm{~Hz}$. Each pin was heated to expected observation temperatures and an emissivity $(\varepsilon)$ calibration curve was created to ensure accurate IR reading.

A Kistler 9170A RCD, a 5070A charge amplifier and Kistler Dynoware acquisition software was used to record and post process $F_{X}, F_{y}$ and $F_{Z}$ forces, where $F_{T}$ and $F_{N}$ are given by Eq. 2 and Eq. 3, respectively. Acquisition rate was set to 20 $\mathrm{kHz}$.

$F_{T}=\sqrt{F_{x}{ }^{2}+F_{y}{ }^{2}}$

$F_{N}=F_{z}$

Fig. 6 shows the typical force profile for a $600 \mathrm{~mm}$ pin traverse (average $F_{T}=388, F_{N}=1369 \mathrm{~N}$ ). The windowing region was set to ensure a steady state region is reached. Forces were averaged across the windowing region shown in Fig. 6 to account for the high acquisition rate noise.

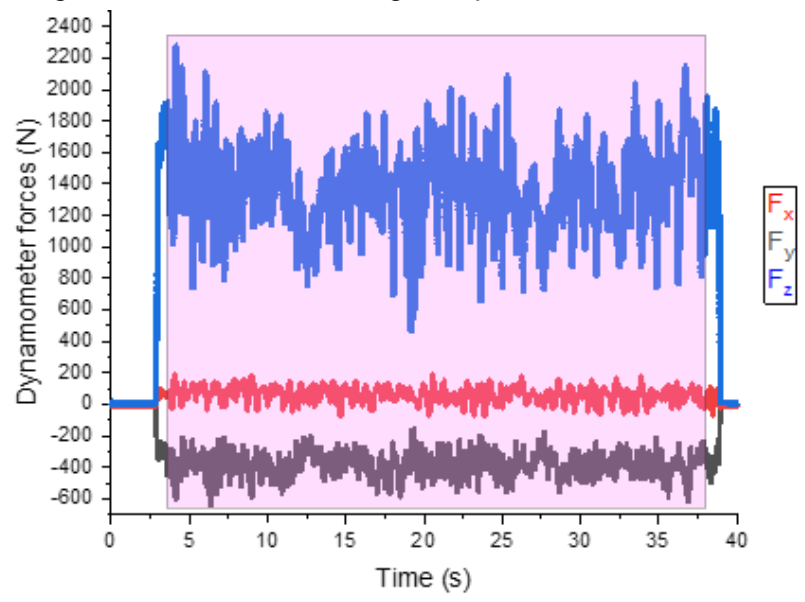

Fig. 6: Typical force profile and region of steady state taken for $\mu_{\text {app }}$ measurement

\subsection{Nanoscale test setup}

Nanoscale friction testing was completed using a Bruker TI980 machine with a Performech II positional controller. 
Prior to scratch testing, samples were sectioned, cold mounted and incrementally polished with higher grades of polishing media, up to a final $0.05 \mu \mathrm{m}$ diamond suspension solution.

Friction was obtained directly through a Berkovich probe (radius range $80-120 \mathrm{~nm}$ ) with pre-heating completed using an $\mathrm{xSOL}$ stage. Scratches were performed at each temperature in resin rich regions as shown in Fig. 7.

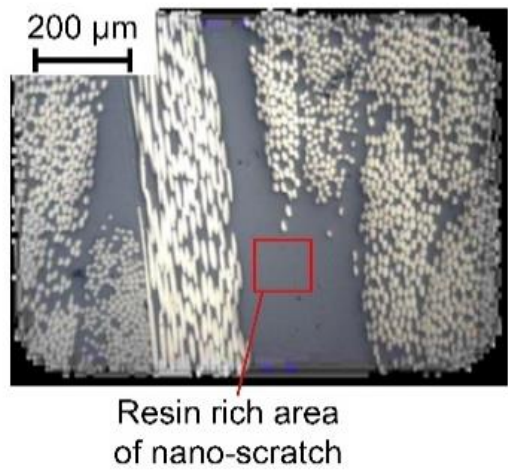

Fig. 7: Typical area for nanoscratch testing for 5320-1 taken during Bruker Nanoindenter TI980 scratch testing

A load function of $100 \mu \mathrm{N}$ at a maximum lateral displacement of $5 \mu \mathrm{m}$ was applied to each scratch in both a forward and backwards pass with a steady state region used to determine the average $\mu_{a p p}$ as shown in Fig. 8.

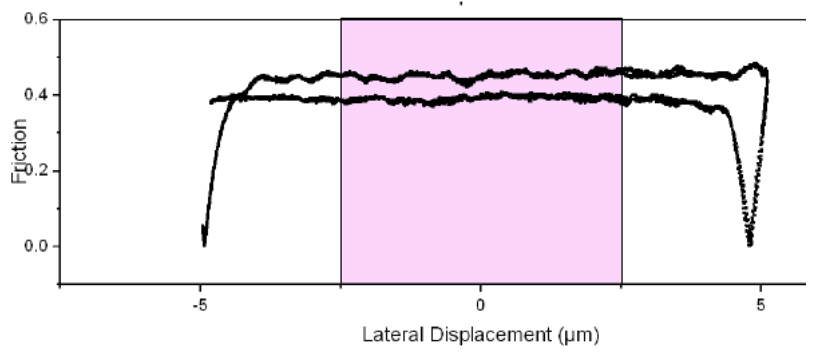

Fig. 8: Typical $\mu_{\text {app }}$ profile of nanoscratch test and region of steady state taken for $\mu_{\text {app }}$ measurement

\section{RESULTS AND DISCUSSION}

\subsection{Pin characterisation}

Tab. 1 shows the results of focus variation observation of pins. It can be seen that the HSS pin has a larger radius than the Carbide and CVD pins which will increase the contact area of the pin when the pin is set to $-0.3 \mathrm{~mm}$ below the surface of the CFRP panel.

Tab. 1: Measured average radius and $S_{a}$ values of pins used throughout trials

\begin{tabular}{ccc}
\hline Pin Material & Radius $(\mathbf{m m})$ & $\boldsymbol{S}_{\boldsymbol{a}}(\boldsymbol{\mu m})$ \\
\hline HSS & $3.118 \pm 0.130$ & $0.289 \pm 0.025$ \\
Carbide & $2.962 \pm 0.032$ & $0.276 \pm 0.012$ \\
CVD & $2.961 \pm 0.013$ & $0.182 \pm 0.004$ \\
\hline
\end{tabular}

$S_{a}$ results show that the CVD pin offers the smoothest surface in line with expectations due to the close structure of the diamond film. A small $S_{a}$ difference of $1.3 \mathrm{~nm}$ exists between the HSS and carbide pins.

\subsection{Feed rate trials}

The $\mu_{\text {app }}$ results of CFRP material, pin material and feed rate variables are shown in Fig. 9. The image shows how the mean $\mu_{\text {app }}$ changes for each variable along with the statistical significance of change (e.g. the material choice has a strong statistical link to $\left.\mu_{a p p}, \mathrm{p}<.001\right)$.

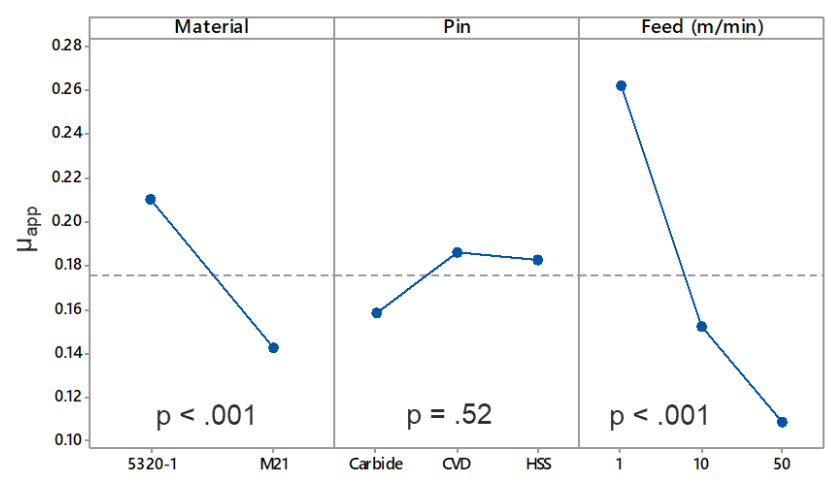

Fig. 9: Main effects plots for CFRP material, pin material and feed rate variables on $\mu_{\text {app }}$

The data means show that the choice of CFRP material has an effect on $\mu_{a p p}(p<.001)$ with a reduction of up to $32 \%$ for the M21 material compared to 5320-1. The architecture of the laminates potentially accounts for this difference. The $5320-1$ being made of $3 \mathrm{k}$ fibre tows with a $36 \%$ resin content and the M21 is made of $6 \mathrm{k}$ fibre tows with a $40 \%$ resin content. As the $T_{g}$ of the materials are similar $(209.3$ and $202.7^{\circ} \mathrm{C}$ ) it is unlikely that $\mu_{\text {app }}$ has been significantly affected by changes in the resin state. However, the exact toughening agents in the resins are unknown and potentially another source for the difference. This highlights the need to include temperature monitoring of the pin and CFRP material.

The pin material does not change the friction $(p=.52)$ which is expected due to the overall low $S_{a}$ values of the pins given in Tab. 1 and the small $S_{a}$ differences $(0.107 \mu \mathrm{m})$ between the roughest (HSS) and the smoothest (CVD) surface. The result also highlights that the slight difference in radius of the HSS compared to carbide and CVD (max. $0.157 \mathrm{~mm}$ ) does not affect $\mu_{\text {app }}$. This is in line with current literature [Mondelin et al. 2010] where different pressures due to higher pin loads/higher contact area were not shown to change $\mu_{\text {app }}$.

The feed rate of the material has a significant effect on $\mu_{\text {app }}$ with a reduction of up to $58 \%$ between 1 and $50 \mathrm{~m} / \mathrm{min}$ which is in agreement with previous authors [Xu et al. 2018] who used a closed loop system. Whilst there is a reduction in $\mu_{a p p}$ for increased feeds, machining often does not use high feed rates as cutting forces increase which can lead to higher tool wear due to larger friction [Shyha et al. 2010]. This would oppose the findings of the feed rate results; for machining it is suggested that $\mu_{\text {app }}$ would rise for high feed rates in contrast to the results shown in Fig.9. It is proposed that the heat generation in the pin on plate trials is different and lower to machining heat. Pin on plate testing allows heat to evacuate due to the small contact area and relatively large available cooling area of the workpiece and pin. During machining, e.g. during drilling, the shank of the tool can be inside the bore of the hole and the tip is engaged with the workpiece, therefore less surface area is available to remove heat from the machining process. This requires further investigation by pre heating the CFRP to simulate temperatures that are more realistic of the cutting process.

Fig. 10 shows the grouped mean results for each of the variables; CFRP material, pin material and feed rate. The data highlights the change in $\mu_{a p p}$ due to CFRP material and feed rate. 


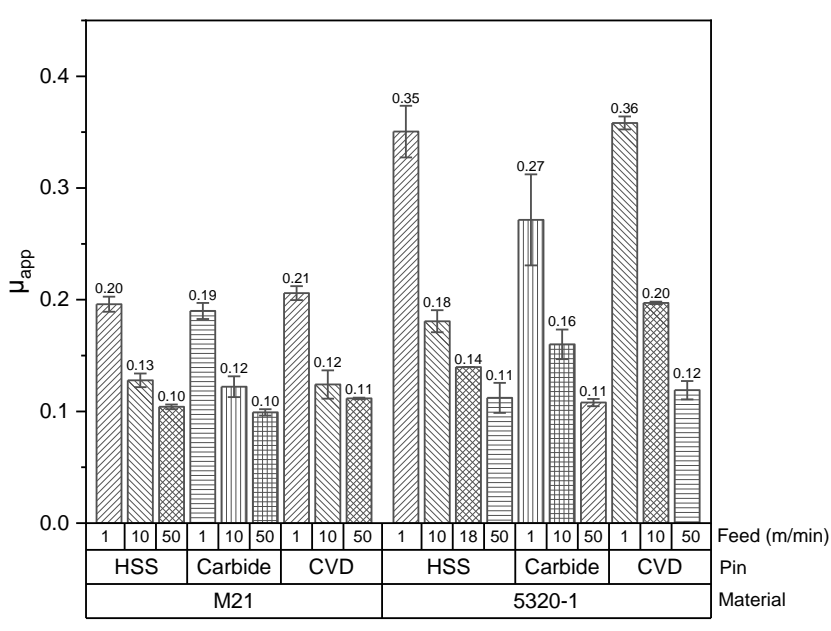

Fig. 10: $\mu_{\text {app }}$ bar chart showing means for minimum of 3 repeats and $\pm 1 S D$

\subsection{CFRP pre-heat trials}

Fig. 11 shows the results of $\mu_{a p p}$ and maximum measured TC temperature inside the pin for M21 material. $\mu_{a p p}$ and maximum measured pin TC temperature increase $(p<$ $.001)$ with higher CFRP pre-heating. It is suggested that the preheating has softened the matrix which has changed the $\mu_{\text {app }}$ of the system. An observation of measured forces shows a reduction of both $F_{T}$ and $F_{N}$ but, proportionally, $F_{N}$ has been reduced by a larger amount, resulting in increased $\mu_{\text {app }}$ values. It is noted that previous authors showed no change in $\mu_{a p p}$ [Mondelin et al. 2010] due to changes in pressure caused by different $F_{T}$ and $F_{N}$ values. However, the pressure changes may not have been significant enough to alter heat involved in the system and change the state of the matrix. As this study has directly changed the state of the matrix to be more representative of machining, it has generated enough changes in $F_{T}$ and $F_{N}$ to alter $\mu_{\text {app. }}$.

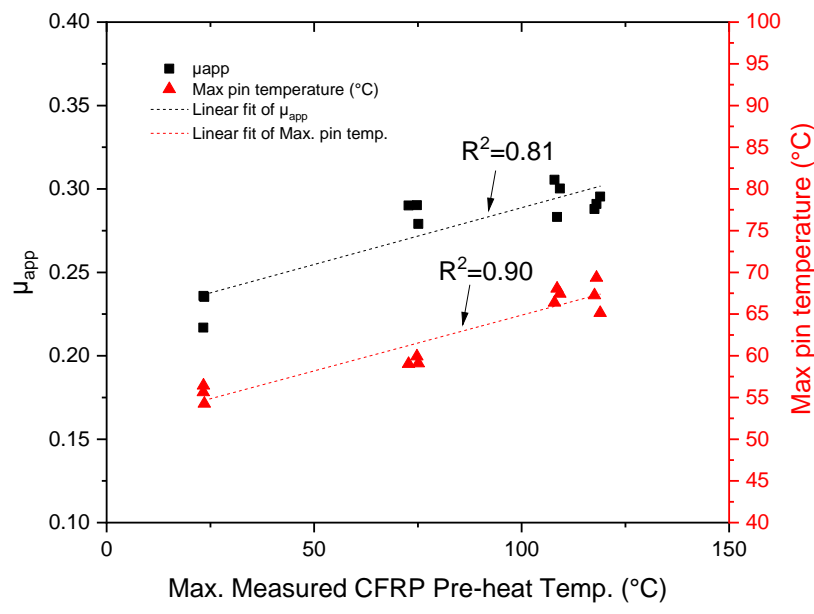

Fig. 11: $\mu_{\text {app }}$ and maximum pin temperature for increasing measured CFRP pre-heat temperature for M21 material with linear fit and corresponding $R^{2}$ value

Fig. 12 shows the results of $\mu_{\text {app }}$ and maximum measured TC temperature inside the pin for 5320-1 material. This follows a similar trend as the M21 material with statistical significance for both $\mu_{a p p}$ and pin temperature $(p<.001)$. $\mu_{\text {app }}$ for both materials increases when additional thermal energy is placed into the contact system. This suggests that for machining operations, cutting should be kept cool in order to reduce friction and thus tool wear.
The IR temperature response of the pins was difficult to measure owing to the reflectivity of the carbide pin that reflected the preheated CFRP panel temperature. However, once the pin passed the end of the panel and no longer reflected the CFRP, the overall trend was the same as the pin TC but with more deviation due to the lower response rate of the camera, thus validating the $\mathrm{TC}$ results.

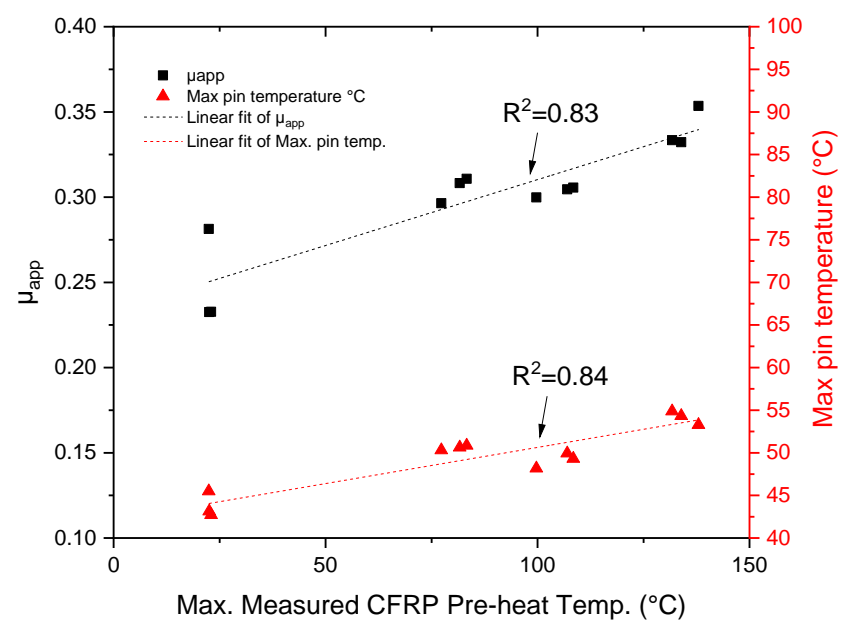

Fig. 12: $\mu_{\text {app }}$ and maximum pin temperature for increasing measured CFRP pre-heat temperature for 5320-1 material with linear fit and corresponding $R^{2}$ value

Fig. 13 shows the typical wear scars of pin on plate testing for different CFRP pre-heat temperatures. It shows that for increased pre-heating temperatures, there are more unbroken fibres. This suggests that the heat involved in the trial changes the matrix from the glassy to a rubbery state. The fibres are then no longer held rigidly and are unable to shear close to or just ahead of the point of pin contact. Instead they break much further away from the point of contact or not at all. Whilst in-line with previous findings [Ashworth et al. 2019] showing that increased CFRP preheating temperature changes the chip formation mechanics, the direct effect on friction has not been previously observed. This result suggests that coolant should be used in order to maintain a glassy matrix state to allow improved surface quality. However, it is suggested that dry coolant is used as other literature shows that liquid based coolants can increase tool wear [Kerrigan and Scaife 2018].

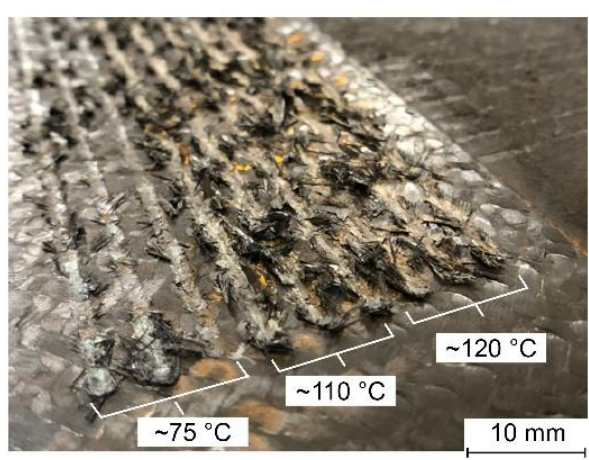

Fig. 13: Increasing levels of surface damage (uncut fibre amount) corresponding to increasing CFRP pre-heat temperature

\subsection{Nanoscale trials}

The results for nanoscale trials on the resin rich area are shown in Fig. 14. It can be seen that as the preheat temperature of the material increases, the friction value 
increases. Whilst there is a visual trend, the significant trend observed in Fig. 11 and Fig. 12 is not present $(p>.05)$. Potentially the change in test method explains this difference as the macroscale test generates additional thermal energy due to the large contact zone and larger feed rate. This additional heat generation is enough to change the matrix properties and subsequent $\mu_{\text {app }}$. Whilst not statistically significant, there is still an upwards trend and with additional testing of preheating temperatures, which approach and exceed $T_{g}$, greater friction changes may become apparent.

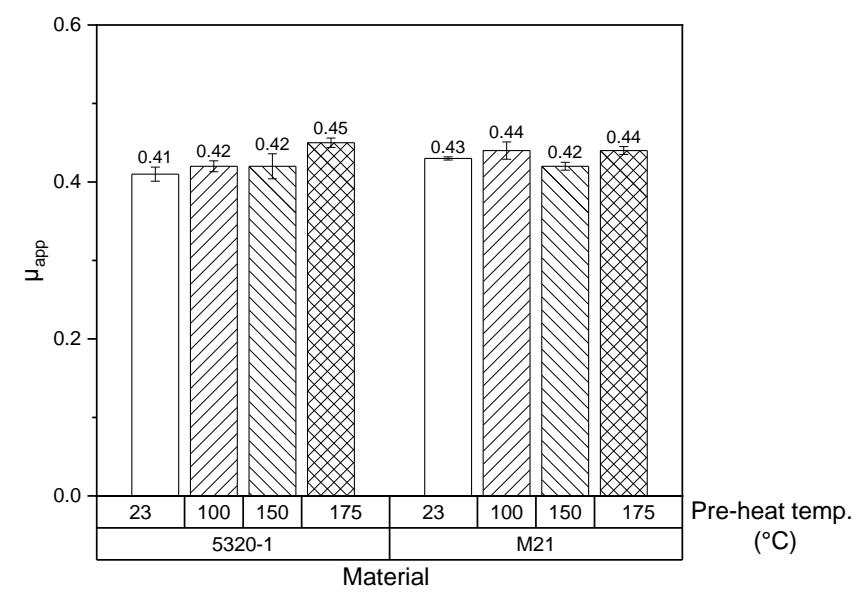

Fig. 14: $\mu_{\text {app }}$ for nanoscratch tests showing increasing friction for increasing CFRP pre-heat temperature. Mean of 4 samples and $\pm 1 S D$ shown

Overall the friction recorded during the nanoscale trials is higher than the macroscale trials. As the nanoscale took place only on the resin, it can be inferred that the resin in the CFRP material is the main contributor to friction, however, further testing on fibre only is required to validate this statement. As to which method is more representative of the process, it is suggested that the nanoscale is more typical. This is due to the edge acuity of cutting tools which may be more representative of contact at small scales. However when edge radius increases due to wear, the macroscale may be more important. If the resolution of the FEA model was able to separate resin and fibre, nanoscale test results may be more representative and useful.

The results of $\mu_{\text {app }}$ for both macro and nanoscale testing suggest that tool wear will increase when cutting temperatures increase. This suggests that some form of thermal control may be required to limit any thermal effect.

\section{CONCLUSIONS}

This experiment has observed $\mu_{\text {app }}$ for CFRP material, pin material, feed speed and CFRP preheat temperature variables with additional pin temperature measurements. As a result of these experiments the following conclusions can be drawn;

- Open loop macroscale friction testing has been successfully used to demonstrate that feed rate, CFRP material and the temperature of the CFRP are all statistically significant variables for a response of $\mu_{\text {app. }}$. Increasing feed rate reduces $\mu_{\text {app }}$ $(p<.001)$, the M21 material provides a lower friction than $5320-1(p<.001)$ and increasing the heat in the CFRP panel increases $\mu_{\text {app }}(\mathrm{p}<.001)$. The pin material did not change $\mu_{a p p}$ with any statistical significance.
- Whilst increased feed rate reduces $\mu_{\text {app }}$ it is suggested that the temperature in these studies are lower than the temperatures experienced during machining. Temperature controlled experiments offer a method to replicate the temperature effects of cutting for friction measurement.

- A Bruker TI980 Tribolndenter has been used to characterise the friction of two materials at elevated temperatures with a trend of increasing $\mu_{\text {app }}$ for larger preheat temperatures. The generation of frictional properties at the nanoscale is a novelty and the results could be harnessed by high resolution FEA which is able to separate fibre and matrix material within its mesh structure.

- The reported $\mu_{\text {app }}$ values of the nanoscale are greater than the macroscale suggesting that the addition of fibre to the contact area in macroscale testing was able to reduce $\mu_{a p p}$. It is therefore suggested that the matrix is the major contributor to $\mu_{\text {app. }}$.

- Relating the results to practical machining of CFRP, it is observed that there is a need to thermally control the cutting system in order to optimise the cutting process. This could utilise super critical $\mathrm{CO}_{2}$ or blown air in order to maintain a dry cutting system.

\section{FUTURE WORK}

Further work to extend the relevance of this work could be completed by;

- Developing a repository of friction information for different fibre and resin types to allow FEA modelling to predict cutting forces for a wide range of CFRP materials. This friction information could be used to form a machinability index for CFRP materials.

- Further work at the nanoscale to observe friction at elevated temperatures towards the $T_{g}$ range. As machining temperatures can be above $T_{g}$, this information would give a valuable comparison to macro friction measurements where the temperature generated by the large contact area potentially exceeds $T_{g}$ at the contact interface zone.

- The additional variables given in Fig. 2 should be investigated to provide an overview of how friction effects the machining of CFRP.

- Further investigations into the contact region of a tool are required and in particular if macro or nanoscale friction results are more appropriate. This is likely to be material dependent, related to the fibre and resin volume of the material and the size of the contact area/cutting edge during machining.

\section{ACKNOWLEDGEMENTS}

The authors would like to thank Niro Nagasaki and Yoshihiro Takikawa from OSG Corporation for supplying carbide and CVD coated carbide pins. Thanks are also extended to the Bruker Corporation, in particular Rhys Jones, Ude Hangen and Jaroslav Lukes. Thanks to Miles Holt from the National Composites Centre for providing DMA analysis. 


\section{REFERENCES}

[Ashby 2011] Ashby, M. F. (2011). Chapter 4 - Material Property Charts. Materials Selection in Mechanical Design (Fourth Edition). M. F. Ashby. Oxford, ButterworthHeinemann: 57-96.

[Ashworth 2019] Ashworth, S., J. P. A. Fairclough, A. R. C. Sharman, J. Meredith, Y. Takikawa, R. Scaife and K. Kerrigan (2019). "Varying CFRP workpiece temperature during slotting: Effects on surface metrics, cutting forces and chip geometry." Procedia CIRP 85: 37-42.

[Ati 2018] ATI. (2018). "Composite Material Applications in Aerospace." INSIGHT, from https://www.ati.org.uk/media/lw4f212o/insight_9composites_amended-2018-09-20.pdf.

[Cepero-Mejias 2020] Cepero-Mejias, F., J. L. Curiel-Sosa, A. Blázquez, T. T. Yu, K. Kerrigan and V. A. Phadnis (2020). "Review of recent developments and induced damage assessment in the modelling of the machining of long fibre reinforced polymer composites." Composite Structures 240: 112006.

[Chardon 2015] Chardon, G., O. Klinkova, J. Rech, S. Drapier and J.-M. Bergheau (2015). "Characterization of friction properties at the work material/cutting tool interface during the machining of randomly structured carbon fibers reinforced polymer with Poly Crystalline Diamond tool under dry conditions." Tribology International 81: 300-308.

[Faraz 2009] Faraz, A., D. Biermann and K. Weinert (2009). "Cutting edge rounding: An innovative tool wear criterion in drilling CFRP composite laminates." International Journal of Machine Tools and Manufacture 49(15): 1185-1196.

[Keerigan 2018] Kerrigan, K. and R. J. Scaife (2018). "Wet vs dry CFRP drilling: Influence of cutting fluid on tool performance." Procedia CIRP 77: 315-319.

[Lorain 2019] Lorain, R., L. Olivier, A. Poggi, F. Valiorgue and J. Rech (2019). "Identification of friction coefficients when drilling titanium TiAI6V4." Procedia CIRP 82: 119123.

[Mondelin 2010] Mondelin, A., B. Furet and J. Rech (2010). "Characterisation of friction properties between a laminated carbon fibres reinforced polymer and a monocrystalline diamond under dry or lubricated conditions." 43(9): 16651673.

[Puls 2012] Puls, H., F. Klocke and D. Lung (2012). "A new experimental methodology to analyse the friction behaviour at the tool-chip interface in metal cutting." 6(4-5): 349-354.

[Sheikh-Ahmad 2008] Sheikh-Ahmad, J. (2008). Machining of polymer composites, Springer.

[Shyha 2010] Shyha, I., S. L. Soo, D. Aspinwall and S. Bradley (2010). "Effect of laminate configuration and feed rate on cutting performance when drilling holes in carbon fibre reinforced plastic composites." Journal of Materials Processing Technology 210(8): 1023-1034.

[Sterle 2019] Sterle, L., F. Pusavec and M. Kalin (2019). "Determination of friction coefficient in cutting processes: comparison between open and closed tribometers." Procedia CIRP 82: 101-106.

[Teti 2002] Teti, R. (2002). "Machining of Composite Materials." CIRP Annals 51(2): 611-634.

[Voss 2017] Voss, R., L. Seeholzer, F. Kuster and K. Wegener (2017). "Cutting Process Tribometer Experiments for Evaluation of Friction Coefficient Close to a CFRP Machining Operation." Procedia CIRP 66: 204-209.

[Voss 2019] Voss, R., L. Seeholzer, F. Kuster and K. Wegener (2019). "Analytical force model for orthogonal machining of unidirectional carbon fibre reinforced polymers (CFRP) as a function of the fibre orientation." Journal of Materials Processing Technology 263: 440-469. [Wang 1995] Wang, D. H., M. Ramulu and D. Arola (1995). "Orthogonal cutting mechanisms of graphite/epoxy composite. Part I: unidirectional laminate." International Journal of Machine Tools and Manufacture 35(12): 16231638.

[Xu 2018] Xu, J., C. Li, M. E. Mansori, G. Liu and M. Chen (2018). "Study on the Frictional Heat at Tool-Work Interface when Drilling CFRP Composites." Procedia Manufacturing 26: 415-423. 